\title{
K-5 Teachers' Perceptions of Engineering Education and Perceived Barriers to Teaching Engineering
}

\section{Dr. Rebekah J. Hammack, Albert Einstein Distinguished Educator Fellowship Program}

Rebekah Hammack holds a BS in Animal Science from The Ohio State University, a MS in Animal Science from Oklahoma State University, and a PhD in Science Education from Oklahoma State University. Rebekah currently serves as an Albert Einstein Distinguished Educator Fellow in the Division of Research on Learning in Formal and Informal Settings at the National Science Foundation and will join the faculty at Montana State University at the completion of her fellowship. She has spent the past 12 years teaching secondary science and engineering in Oklahoma, and is a 2014 recipient of the Presidential Award for Excellence in Mathematics and Science Teaching. 


\title{
K-5 Teachers' Perceptions of Engineering Education and Perceived Barriers to Teaching Engineering (Fundamental)
}

\begin{abstract}
The Next Generation Science Standards call for the infusion of engineering content and practices within elementary science curriculum. This mixed methods study explored elementary teachers' perceptions about incorporating engineering within K-5 classrooms as well as the barriers they perceive to doing so. Results indicated that most elementary teachers support the inclusion of engineering within the science standards for elementary grades. Teachers describe lack of preservice and in-service training, lack of background knowledge, lack of materials, lack of time for planning and implementing lessons, and lack of administrative support as barriers to implementing engineering activities within their classrooms.

*The views and opinions of the speaker expressed herein do not necessarily state or reflect those of the U.S. Government or any agency thereof.

\section{Introduction}

The Next Generation Science Standards (NGSS) incorporated engineering practices into K-12 science standards [1], and because NGSS calls for K-12 teachers to infuse engineering into their science classrooms, action must be taken to ensure teachers are prepared to successfully implement the new standards. Waiting until students reach middle or high school to incorporate engineering practices into the classroom is too late, as students begin making career decisions and developing vital academic skills in elementary school. This makes the elementary years an important time for introducing engineering, yet little is known about how prepared elementary teachers are to integrate engineering practices into their science lessons.

Most teacher preparation programs do not prepare elementary teachers to incorporate engineering practices into their classrooms, and professional development opportunities focused on engineering for elementary teachers are limited. Determining the perceptions elementary teachers hold about K-5 engineering and the barriers they believe limit their abilities to implement engineering into their teaching will be necessary to ensure that elementary teachers receive the professional development and support needed to implement the engineering components of NGSS.
\end{abstract}

\section{Purpose of the Study}

The purpose of this study was to identify the perceptions that elementary teachers have towards K-5 engineering as well as identify any barriers that K-5 teachers believe might prevent them from successfully teaching engineering in their classrooms. 


\section{Related Literature}

The need to create a STEM pipeline as well as ensure students leave high school with a basic level of STEM literacy make the incorporation of engineering into the K-12 classroom important. Many students begin making decisions about career paths before reaching middle school [2], making exposure to STEM careers and activities during the elementary years important. The infusion of engineering standards within NGSS implies that all K-5 educators should incorporate engineering within their science lessons, however K-5 engineering education is a relatively new field of study.

Teachers are uncomfortable teaching what they do not know or are unfamiliar with [3]. Many prekindergarten through eighth grade teachers have limited STEM content knowledge [3] which may result in an avoidance of teaching engineering. The familiarity with engineering construct is not well developed in the research literature and studies are limited to those using the instrument developed by Yasar and colleagues. Yasar et al. [4] used a Likert scale instrument to measure K-12 teachers' familiarity with engineering, engineering design, and technology (DET). Most teachers in the study had low familiarity with DET, which was attributed to lack of knowledge, lack of training, lack of administrative support, and lack of time for learning about DET. Subsequent studies using the DET instrument reported similar findings [5], [6].

There is a lack of research literature devoted to the barriers of implementing engineering at the K-5 level. However, the literature related to the barriers to implementing science in the elementary curriculum is more complete. Because engineering is included within NGSS, the barriers to teaching science may provide insight into possible barriers to teaching engineering. When describing the barriers to implementing inquiry science at the elementary level, many teachers list lack of content knowledge [7], [8]; inadequate pre-service training [9]; and a lack of resources, planning time, and instructional time (often due to a focus on tested subject matter) as inhibiting factors [9] - [10]. Further, Blanchard et al. [9] reported that teacher comfort related to the inquiry teaching methods was the most significant variable in determining whether teachers would teach using inquiry[9]. In fact, when interviewing award winning science teachers from grades K-12, Burton and Frazier [7] reported that all respondents said elementary teachers lacked the content and pedagogical knowledge required to teach inquiry and many were intimidated by inquiry and avoided teaching with it.

Overall, the research literature devoted to the barriers teachers have related to implementing engineering activities at the elementary level have not been fully explored. The current study addresses this void in the literature by describing the barriers K-5 teachers perceive as limiting their abilities to teach engineering to their students.

\section{Methodology}

This study is part of a larger dissertation study [12] that investigated elementary teachers' perceptions of engineering and engineering design, as well as their preparedness to teach engineering. During the first phase of the larger study, participants completed an online questionnaire containing selected response, open-ended, and Likert questions. The results from Phase 1 were used to finalize the interview protocols used during the individual and focus group 
sessions that took place during Phase 2 of the study. This paper focuses on the Phase 1 survey results related to participants' perceptions of K-5 engineering and perceived barriers to implementing engineering at the K-5 level.

\section{Measures}

No individual questionnaire existed that would address all of the research questions that were a part of the larger study. As a result, the researcher combined subscales form existing instruments in order to gather data pertinent to all of the research questions. Because the author sought to identify the barriers teachers might perceive to implementing engineering, the Barriers to Integrating DET subscale from the Design Engineering and Technology Survey [13] was selected. Further, modified versions of some questions from the Texas Poll of Elementary School Teachers [14] were included to identify additional information that may impact teachers' perceptions of K-5 engineering and barriers to implementation.

Design Engineering and Technology Survey, DET. The DET, originally developed by Yasar, Baker, Robinson-Kurpius, Krause, and Roberts [4] and re-evaluated by Hong, Purzer, and Cardella [13], is a 40 item, five-point Likert instrument used to measure teachers' perceptions of engineering and familiarity with teaching engineering, engineering design, and technology. Prior to data analysis in the current study, the internal consistency of the Barriers to Integrating DET subscale was determined using Chronbach's $\alpha$. The Chronbach's $\alpha$ for the current study of $\alpha=$ 0.63 was slightly lower than the value of $\alpha=0.68$ reported by Hong et al. [13].

Texas Poll of Elementary School Teachers. The Texas Poll of Elementary School Teachers was a phone interview questionnaire designed to gather information that could be used to improve science teaching at the elementary level [14]. For the current study, questions 3, 4, 5, $6,9,10,26$, and 27 of the Texas Poll were modified by replacing the word "science" with "engineering." For example, item 3 on the Texas Poll "Do you believe science is a high priority in you school?" was changed to "Do you believe engineering is a high priority in your school?"

The majority of the Texas Poll questions were selected response, with three of the Texas Poll questions followed with "Please elaborate on your previous response." The questions containing follow ups were: "Are you satisfied with the extent to which your school provides you with instructional materials to teach engineering? Please elaborate on your response," "What are the two most important things that would help you improve engineering teaching in your classroom. Please elaborate on your response," and "Assume you have been appointed to a national task force that wishes to construct a new preservice teacher methods course devoted explicitly to teaching engineering in elementary schools. What two things would you recommend they stress in developing this new preservice course? Please elaborate on your response."

\section{Participants}

A link to the online questionnaire was emailed to all Oklahoma K-5 public school teachers $(n=16,546)$ whose contact information was on file with the Oklahoma State Department of Education (OKSDE), however 1,008 emails were returned undeliverable. The questionnaire was completed by 542 participants who were responsible for the science instruction of their students, resulting in a $3.5 \%$ response rate. A review of the sample and state K-5 teaching 
population presented in Table 1 indicate that the percentage of participants identified in each demographic subcategory fell within a few percentage points of the corresponding state population demographic. Overall, this indicates that the sample was representative of the state population with regard to education level, gender, grade level taught, years of teaching experience, and geographic distribution of teachers. 
Table 1.

Demographics of Oklahoma K-5 Teacher Population and Study Sample

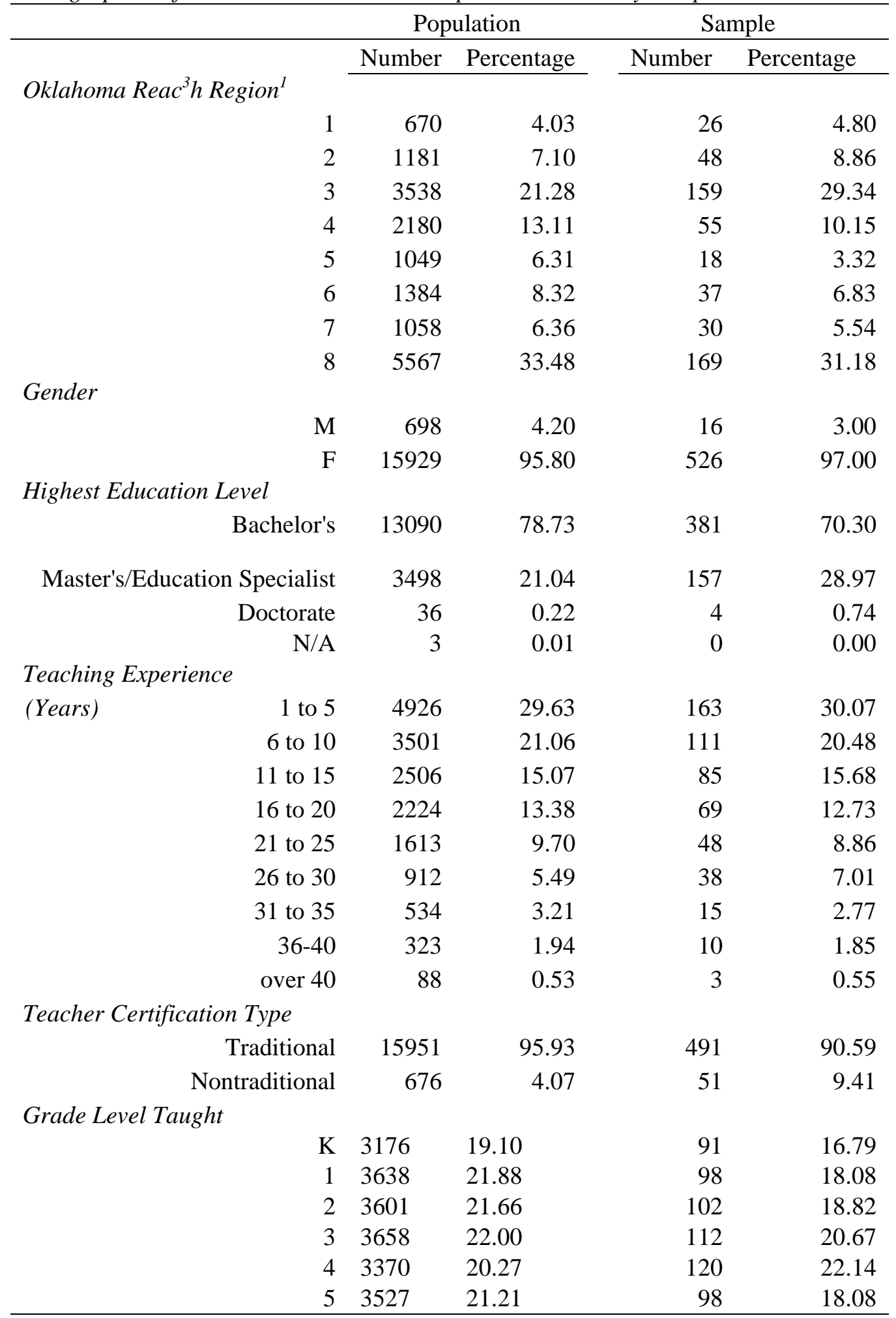

\footnotetext{
${ }^{1}$ The Oklahoma Reac ${ }^{3} h$ regions were used to determine the geographical representation of the state. A map of the Reac ${ }^{3}$ h regions can be found at http://ok.gov/sde/reac3h-network.
} 


\section{Data Analysis}

DET analysis. Participant responses for the DET subscale were transferred to SPSS version 22. The researcher analyzed data to yield frequencies of responses to each subscale question. Oneway ANOVA was used to determine if any significant differences existed on subscale scores of different demographic groups including ethnicity, gender, years of teaching experience, grade level taught, pathway to certification, education attainment level, and geographic region.

Texas Poll analysis. All selected response questions were transferred to SPSS and analyzed to yield frequencies of respondents choosing each response category. Responses to the three openended questions were printed onto cards which were used during the coding process [15]. First, attribute coding was used to log essential demographic information about the participants for future reference [16]. Each card was coded with the participant's gender, ethnicity, years of teaching experience, education attainment level, geographic region, pathway to certification, and grade level taught. The researcher then read through each response and compiled an initial list of codes to use during coding. Next, as described by Saldana [16], the researcher used the initial code list to complete a round of descriptive coding. During this initial round of descriptive coding, additional codes were generated and added to the preliminary code list and code frequencies were determined. The frequencies with which each code appeared in the data were based on the number of participants who used a particular code, not the number of times that the code appeared [17].

\section{Results}

Figure 1 displays participant responses to the Design, Engineering, and Technology, DET, subscale questions, which are a measure of how strong of a barrier to teaching engineering participants perceive each of the areas to be. The majority of participants strongly agreed that lack of time to teach DET (57\%), lack of teacher knowledge of DET (50\%), and lack of training in DET (57\%) are barriers to implementing engineering into their classrooms. While administrative support was also reported as a barrier by approximately half of the participants, it was not reported as a strong barrier as frequently as the others. No significant differences were identified for the subscale scores of different demographic groups.

When asked if participants had attended engineering focused professional development (PD) during the last three years, $85 \%$ reported that they had not. Of the $15 \%$ who had attended engineering focused PD, only $40 \%$ reported that their district paid for them to attend the PD. Examples of engineering focused PD that participants attended included Project Lead the Way, STEM workshops developed by the Oklahoma Energy Resource Board, and robotics trainings such as Botball and FIRST Lego League. Many participants could not remember the name of the PD they attended and simply called it a STEM training.

Figure 2 displays participant responses to the modified Texas Poll question "Do you believe engineering is a high priority..." Overall, participants did not believe that engineering was a priority in their schools, in their school districts, to the parents in their schools, or to the communities where their schools were located. 


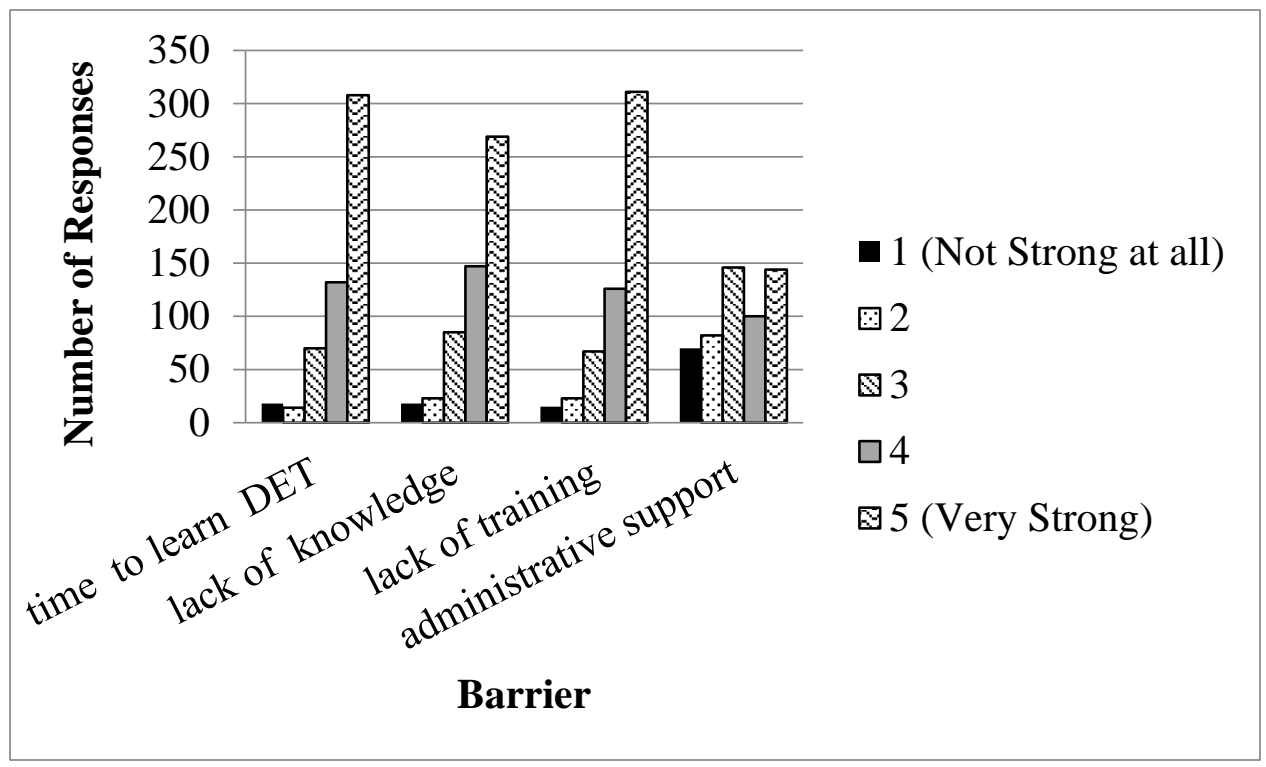

Figure 1. Frequency of participant responses to items on the Barriers to Integrating Design/Engineering/Technology subscale.

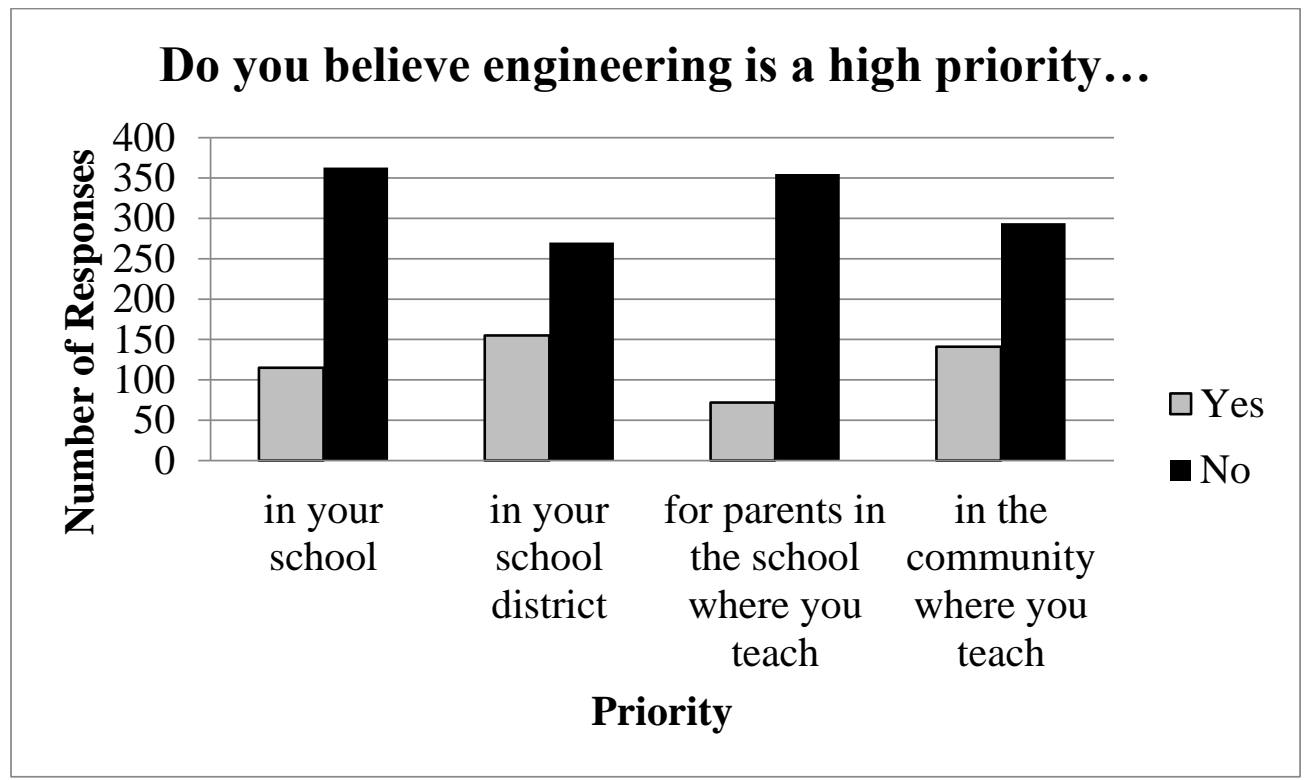

Figure 2. Participant responses to perceived priority level of engineering.

When asked if they were satisfied with the extent to which their school provides instructional materials for teaching engineering, $81 \%$ of participants said they were not satisfied. Interestingly, of the 103 (out of 542) participants who were satisfied, 35\% commented that their district did not provide any resources, but because they do not teach engineering, they have no need for instructional materials. Those who stated that they were unsatisfied mentioned that there was too much emphasis placed on reading and mathematics, so materials and training for science and engineering were not offered. One participant wrote, "There is really nothing provided and 
for the most part it boils down to 'it's not tested in my grade, so don't spend too much time on it'." Another wrote, "As far as I know, we have no support in this. We do not even have sufficient support in science...the last time we received new teaching materials was in the 1990s. I am also missing one of my science textbooks and have asked for it to be replaced the past 3 years...hasn't been replaced yet."

Improving ability to teach engineering. Participants were asked to identify the two most important things that would help improve their abilities to teach engineering in their classrooms. Responses are displayed in Figure 3. Training and information about how to teach engineering was the most commonly selected item (76\%), followed by additional materials $(56 \%)$, guidance in what to teach in engineering classes $(42 \%)$ and support for teaching engineering (18\%). Nine percent of participants selected "other" and listed additional time for planning and/or teaching engineering as an area for improvement. When asked to elaborate on their answers, participants' responses fell within six categories: materials, support, knowledge and training, time, guidance, and not appropriate for elementary. Many participants' responses fell within more than one category and were counted in each category in which they fell.

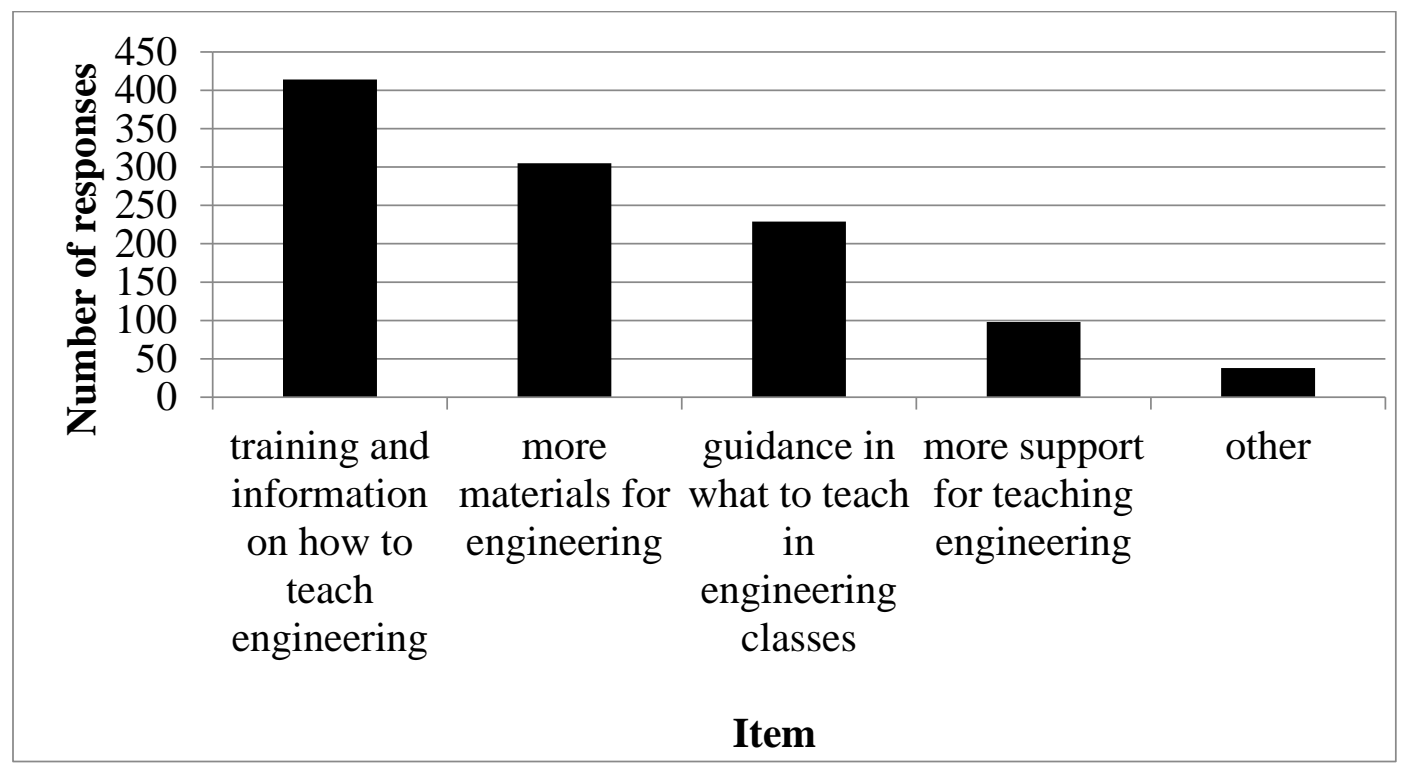

Figure 3. Items identified as important for improving engineering teaching.

Materials. Responses in this category focused on a lack of physical materials or curriculum materials for teaching engineering. One participant stated, "I don't know of anything in my classroom I could use right now to teach an engineering lesson with." Another participant wrote, "Without the proper supplies it makes it extremely hard to teach these standards."

Support. Responses included in this category related to the lack of administrative support for teaching engineering or the understanding that engineering was not encouraged or required to be taught. For example, one participant stated, "Engineering is not in our PASS skills [state standards] for my grade level. If it was in the PASS we would teach it." One teacher stated, "I haven't even been told we are supposed to teach about this subject." Others mentioned support for teaching engineering to certain groups of students, "Engineering lessons are reserved 
for students who are a part of the Gifted and Talented program," but not for others, "special education is not encouraged to teach it." Another participant wrote, "We just don't talk about science much at all. We're pretty much told to focus on math and reading since those are two subject areas we test in each year. We do teach science for half the year, but I don't think the administration cares how, when, or how much it is taught."

Knowledge and training. Responses in this category were related to participants' lack of knowledge of engineering. Some participants said that they knew so very little about engineering that they did not know what they needed. As one teacher stated, "I don't know what I need to teach it but my district is underfunded so I don't even know that we have the materials to teach it if I knew what to do." Many participants said that they need to understand engineering well enough to teach it, "We need to understand what we are supposed to teach before we could possibly introduce it to our classes." Other teachers mentioned being intimidated by their lack of engineering knowledge, which resulted in not teaching it, "I don't know. I have no idea about teaching any kind of engineering. I do not attempt nor would I attempt to teach engineering."

Time. Responses in this category focused on a lack of time for preparing or teaching engineering. Many participants said that they did not have time to teach engineering because they had to focus on content that would be on state assessments, "This is not done in our elementary school for time is spent on focusing on the skills the students will be tested on." Some participants were frustrated with the amount of material to be covered and the lack of time to do it in, "We already have too much on our plate. This would be one more thing..." As another teacher stated, "I don't have time to find materials, produce lessons, and research how to do it all myself."

Guidance. Many participants said that they would be willing to teach engineering to their students if they were given guidance on what was appropriate to teach at their grade level and how to implement it, "I would need some ideas of engineering projects appropriate to the $3^{\text {rd }}$ and $4^{\text {th }}$ grade and more time to do it in." Another participant stated, "More guidance to understand what is actually [considered] engineering."

Not appropriate for elementary. A surprising category to emerge from the data was the idea that engineering should not be incorporated into the elementary curriculum. Participants were asked to elaborate on the items they needed to better enhance their abilities to teach engineering, so it was expected they would describe items needed to help them teach engineering, yet some responded by saying that engineering should not be taught in elementary school. One participant stated, "We must stay focused on reading and math basics for the children's sake." Another wrote, "At this age level, I don't understand the need or reason for engineering when basic facts are no longer of importance." Others stated that engineering is "not appropriate in kindergarten," and "There is so much we already have to teach that expecting design and engineering when kids can't even pass writing and reading tests is just crazy."

Elements of preservice engineering methods course. Participants were also asked to identify the two most important elements that should be included in a preservice engineering methods course and to elaborate on their answer. Figure 4 illustrates participants' responses. How to teach engineering and how to use materials to teach engineering were the most 
frequently chosen elements. For the "other" category $(n=28)$, participants listed things like lesson plan ideas, hands-on training, and ideas for funding. Interestingly, one participant who chose other wrote, "not important for my grade and social status children." When participants were asked to elaborate, their responses fell into five categories: how to use materials, hands-on training, how to find resources, background knowledge, and not appropriate for elementary. Responses often fell within more than one category, in which case they were included in each category in which they fit.

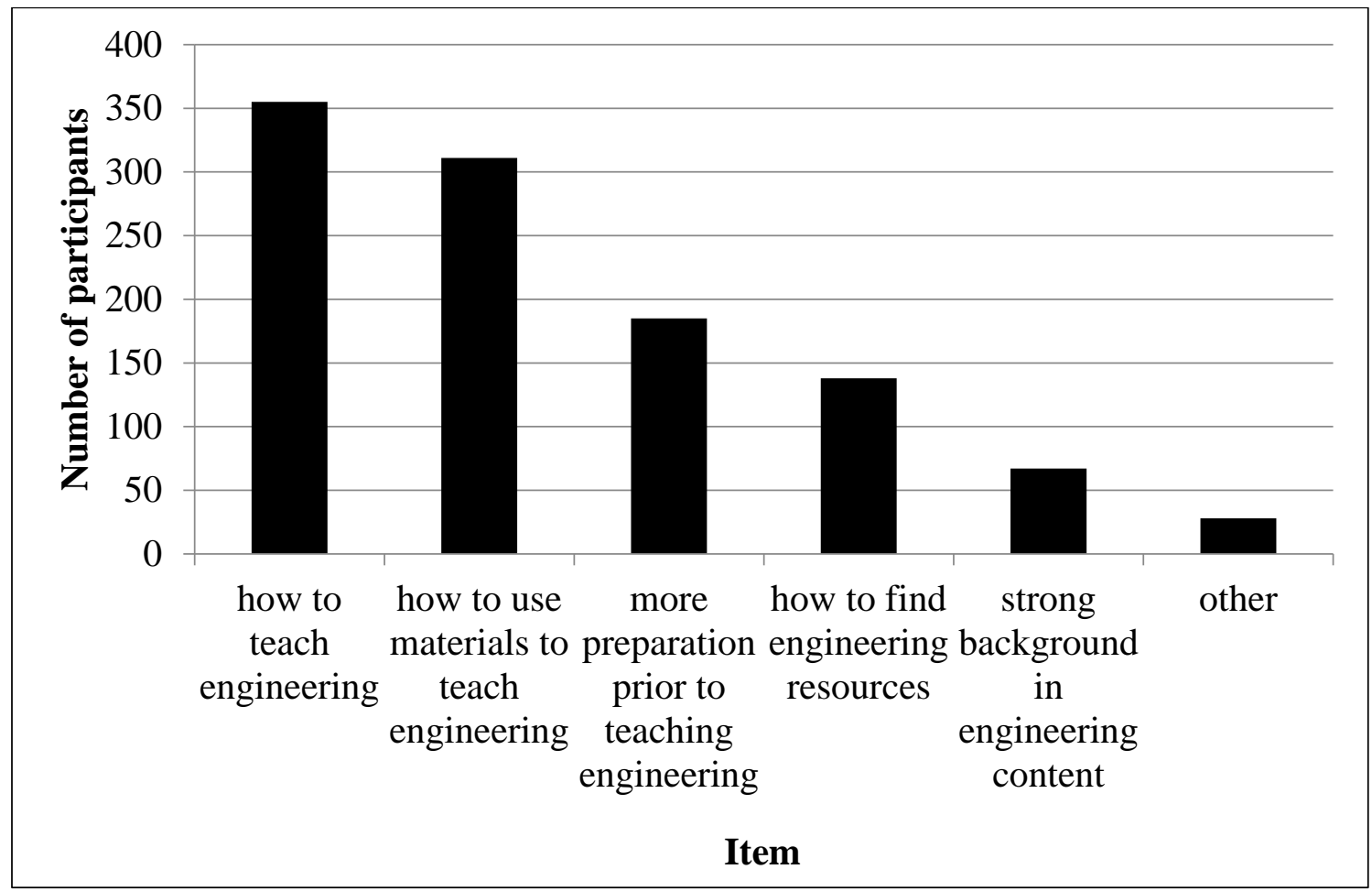

Figure 4. Elements identified as important to include in a preservice engineering methods course.

How to use materials. Many participants stressed the importance of being trained on how to use materials to teach engineering, "Materials without knowledge about how to use them leads to students not learning, and knowledge without proper materials just scratches the surface with regards to students needing hands-on learning." Another participant wrote, "Providing materials is not enough. Many rooms have excess materials. Teachers must be taught how to use materials."

Hands-on and applicable training. The importance of hands-on training that is applicable to the classroom was also stressed, "Preservice teachers need real life experiences in teaching engineering lessons, rather than lectures over the topic." Another participant wrote, "I would like to be shown explicit ways to introduce and to implement engineering in the classroom. Often times these courses go on and on about what engineering is, but I need to know how to implement it in an elementary classroom. Show me examples of lessons." 
How to find resources. This category contained responses related to being able to locate resources when they are needed, "Since engineering is now part of the standards, I think how to teach engineering would be important in a class and since curriculum specifically for engineering will not always (or even usually?) be provided, I think how to find engineering resources and/or how to use other materials to teach engineering would also be important." Another participant wrote, "Knowing where to find the resources is a very important component in including it in the classroom. When schools do not provide resources, teachers should know how to teach engineering."

Background knowledge. Many participants mentioned the importance of teachers understanding the content knowledge they must teach. For example, "Teachers need to understand what you mean by engineering. We try and teach our kids to think, but what type of engineering projects would the state approve as 'good' and teachers think are 'good' could be very different." Another participant wrote, "If teachers don't have background knowledge and understand it themselves, they WILL NOT implement their training in their classrooms!"

Not appropriate for elementary. This category contained responses related to reasons why engineering is not needed in elementary school or negative responses related to engineering, "Why would we want to teach engineering when the children are having difficulty learning to read, write and do basic math?" Another participant wrote, "I still think this is asking more than what is reasonable." Others responded, "I didn't become an elementary teacher thinking I would teach elaborate engineering" and "I feel teachers have enough to teach without adding more to our plate, with students that can't even read."

\section{Discussion}

As previously stated, the purpose of this study was to identify the perceptions that K-5 teachers hold about engineering education as well as the barriers they believe prevent them from implementing engineering into the classroom.

\section{Research Question 1: What perceptions do in-service elementary teachers hold about K-5 engineering education?}

Questionnaire responses indicated that most participants felt K-12 engineering was not a priority in their schools, school districts, communities, or for the parents at their schools. Participant comments also suggested that they felt engineering was not a priority to administrators and the state department of education. Rather, the participants perceived that the focus of school administration was on state mandated assessments in mathematics and reading. Similar findings have been reported in the research literature related to lack of time for teaching inquiry science due to a focus on mandated tests [9], [10].

While analyzing the questionnaire responses, it became clear that many participants were supportive of engineering education. However, it was also obvious that participants held misconceptions about engineering which may have influenced their responses. Some participants did not feel engineering should be included in K-5 curriculum. These responses appeared to be based on a lack of understanding of engineering and the engineering practices described in 
NGSS. Comments about engineering being just another topic added onto an already overflowing plate, indicate that teachers are unaware of the infusion approach taken by NGSS with regard to engineering [1]. Engineering practices are woven within NGSS and linked to science content standards that are already being taught in K-5 classrooms, therefore the addition of engineering content and practices to NGSS does not add additional requirements to the science standards already being taught. Although NGSS is not adopted in Oklahoma, the new Oklahoma Academic Science Standards, OAS-S, mirror NGSS. Further, many participants stated that even though they did not receive any resources for teaching engineering, they were satisfied with this because they did not teach engineering anyway. This reveals that teachers do not understand the science standards they are required to teach as part of OAS-S, which require them to be engineering teachers.

Some participants' responses indicated that teachers held misconceptions about the difficulty or nature of engineering. For example, a few participants mentioned that it is not appropriate to teach engineering when they have students who struggle with basic reading and math skills. Again, this shows a lack of understanding of how engineering can be infused within the existing curriculum. In fact, the incorporation of engineering into lessons has been shown to be an effective way to teach mathematics and improve scores on mathematics achievement tests at the elementary level [18], [19].

While some elementary teachers do not see the value of incorporating engineering education at the elementary level, the questionnaire responses suggest that many elementary teachers do support the idea of infusing engineering into elementary curriculum and view engineering as beneficial to their students. In fact, many participants stated that if they were given the training and materials they would enjoy teaching engineering to their students. It is important to note however, that a lack of understanding of how the engineering standards are designed to be implemented and the perceived lack of priority that has traditionally been placed on engineering at the elementary level may have impacted teachers' views relative to both sides of this issue.

\section{Research Question 2: What factors do in-service elementary teachers perceive as barriers to teaching engineering and engineering design?}

As expected, the barriers reported in the research literature related to teaching inquiry science were similar to those identified in the current study, namely lack of time [10], lack of knowledge [8] lack of training [9], and lack of resources [10]. Many of the issues related to these barriers are overlapping, such as lack of time to find materials or lack of training on how to use materials.

Participants stated that they did not have enough time in the school day to teach all of the required curriculum components. Similar findings have been reported pertaining to teaching inquiry science [9], [11]. Lack of time for planning was another common barrier. Most teachers spend hours planning before they teach a new lesson. They take time to research and go over the content to make sure they fully understand it, gather and set up materials, and create assessments for the lesson. Further, the fewer resources a teacher has for a particular topic, the more time he or she must spend planning for those lessons by searching for and gathering curriculum 
resources. Elementary teachers are planning lessons for multiple subjects, which takes a great amount of time each week. This, coupled with the fact that most teachers do not have engineering curriculum resources available to them or even know where to look for those resources, could make finding enough time to adequately prepare engineering lessons difficult to come by.

Lack of knowledge about engineering and training to teach engineering were also mentioned as barriers to implementing the new standards into the curriculum. Questionnaire responses indicated that most participants did not feel that their preservice program provided them with the background knowledge and training necessary to teach engineering. When describing the components to include in a preservice program, participants asked for relevant hands-on training on how to use materials, as well as training on where to locate available resources. In addition, teachers need training to better understand the types of materials that can be used to teach engineering activities, and shown ways to incorporate high quality design activities into their classrooms by using inexpensive supplies such as paper, index cards, paperclips, and straws.

Any new program, curriculum, or initiative that is given to teachers to enact will require training and support. However, it can be argued that requiring elementary teachers to implement an entirely new content area in which they have no professional training or experience with (such as engineering) would present additional challenges than implementing a new curriculum in a subject in which they have considerably more training and experience (such as reading). Additional research related to the specific barriers of implementing new curriculum is warranted.

\section{Strengths and Limitations}

A strength of the current study was that the sample closely mirrored the state K-5 teacher population with regard to geographic region, education level, pathway to certification, gender, teaching experience, and grade level taught. The study does have limitations. First, data was limited to the members of the population who chose to participate, and because the data was selfreported there could be response bias. Additionally, only public school teachers in Oklahoma were included in the study, which could limit the generalizability to teachers from private schools or those employed in other states.

\section{Conclusion and Implications for Future Research}

Administrators at the local and state level need to be aware of these findings. If administrators are going to ask teachers to teach engineering standards in K-5, then they must take steps to provide teachers with the tools they need to do so. This will require the development of curriculum and instructional resources and training on how to infuse engineering within already existing science lessons. Further, a website containing links to quality online engineering education resources needs to be developed and maintained, whether it be by a state or federal agency, or educational outreach organizations.

If elementary teachers are expected to teach NGSS as it is written, then they must be

provided with the necessary funding to do so. At the state and national level, funding needs to be 
set aside for science and engineering education to develop engineering resources, provide professional development, and purchase materials for classroom use. Additional funding to provide long term support to teachers, such as follow-up trainings and professional learning communities, will also be required.

Preservice coursework in engineering education needs to be developed and offered to elementary education majors. While the current study addressed what teachers would like to see in a preservice engineering education course, further research will be needed to determine the best components of a preservice course.

To help address the future STEM pipeline and mainline needs, the Next Generation Science Standards call for the infusion of engineering activities into elementary science curriculum. While many elementary teachers support the use of engineering activities in their classrooms, there are numerous barriers preventing them from doing so. In order to ensure that NGSS are incorporated into elementary classrooms as they were intended, elementary teachers must be provided with the necessary training, resources, and support.

\section{References}

[1] NGSS Lead States. (2013). Next Generation Science Standards: For states, by states. Washington, DC: The National Academies Press.

[2] Wyss, V. L., Heulskamp, D., \& Siebert, C. J. (2012). Increasing middle school student interest in STEM careers with videos of scientists. International Journal of Environmental \& Science Education, 7(4), 501-522.

[3] Brophy, S., Klein, S., Portsmore, M., \& Rogers, C. (2008). Advancing engineering education in P-12 classrooms. Journal of Engineering Education, 97(3), 369-387. doi: 10.1002/j.21689830.2008.tb00985.x

[4] Yasar, S., Baker, D., Kurpius-Robinson, S., Krause, S., \& Roberts, C. (2006). Development of a survey to assess K-12 teachers' perceptions of engineers and familiarity with teaching design, engineering, and technology. Journal of Engineering Education, 95(3), 205-216. doi: 10.1002/j.2168-9830.2006.tb00893.x

[5] Hsu, M-C., Cardella, M. E., Purzer, S., \& Diaz, N. M. (2010). Elementary teachers; perceptions of engineering and familiarity with design, engineering, and technology: Perspectives from a national population. Proceedings of the 2010 American Society for Engineering Education Annual Conference \& Exposition, Louisville, KY.

[6] Hsu, M-C., Purzer, S., \& Cardella, M. E. (2011). Elementary teachers' views about teaching design, engineering, and technology. Journal of Pre-College Engineering Education Research, 1(2), 31-39. 
[7] Burton, E. P., \& Frazier, W. M. (2012). Voices from the front lines: Exemplary science teachers on education reform. School Science and Mathematics, 112(3), 179-190. doi:

10.1111/j.1949-8594.2011.00131.x

[8] Sexton, S. (2013). Narratives of place: Provisional teachers' experiences in science. Science Education International, 24(3), 361-376.

[9] Blanchard, M. R., Osborne, J. W., Wallwork, C., \& Harris, E. S. (2013). Progress on implementing inquiry in North Carolina: Nearly 1000 elementary, middle and high school science teacher weigh in. Science Educator, 22(1), 37-47.

[10] Cartwright, T. (2014). Confronting barriers to teaching elementary science: After-school science teaching experiences for preservice teachers. Teacher Education \& Practice, 27(2/3), 464-487.

[11] Santau, A. O., \& Ritter, J. K. (2013). What to teach and how to teach it: Elementary teachers' views on teaching inquiry-based, interdisciplinary science and social studies in urban settings. The New Educator, 9(4), 255-286. doi. 10.1080/1547688x.2013.841498.

[12] Hammack, R. (2016). Elementary teachers' perceptions of engineering, engineering design, and their abilities to teach engineering: A mixed methods study (Doctoral dissertation). Retrieved from ProQuest Dissertations. (10188936)

[13] Hong, T., Purzer, S., \& Cardella, M. (2011). A psychometric re-evaluation of the Design, Engineering and Technology (DET) Instrument. Journal of Engineering Education, 100(4), 800818. doi: 10.1002/j.2168-9830.2001.tb00037.x

[14] McNamara, J. (1999). The Texas poll of elementary school teachers: Part one. International Journal of Educational Reform, 8(2), 186-200.

[15] Creswell, J. W. (2007). Qualitative inquiry \& research design: Choosing among five approaches (2nd ed.). Thousand Oaks, CA: Sage Publications.

[16] Saldana, J. (2013). The coding manual for qualitative researchers (2nd ed.). Thousand Oaks, CA: Sage Publications.

[17] Namey, E., Guest, G., Thairu, L., \& Johnson, L. (2008). Data reduction techniques for large qualitative data sets. In G. Guest \& K.M. MacQueen (Eds.), Handbook for team-based qualitative research (pp. 137-61). Lanham, MD: AltaMira Press.

[18] Hotaling, L., McGrath, B., McKay, M., Shields, C., Lowes, S., Cunningham, C., Lachapelle, C., \& Yao, S. (2007). Engineering our future New Jersey. Proceedings of the 2007 American Society for Engineering Education Annual Conference \& Exposition, Honolulu, HI.

[19] Parsons, C., O’Hare, D., Little, R., Van Driessche, P., Parsons, K., Barger, M., \& Gilbert, R. (2007). Supporting math and science through engineering in elementary education. Proceedings 
of the 2007 American Society for Engineering Education Annual Conference \& Exposition, Milwaukee, WI. 